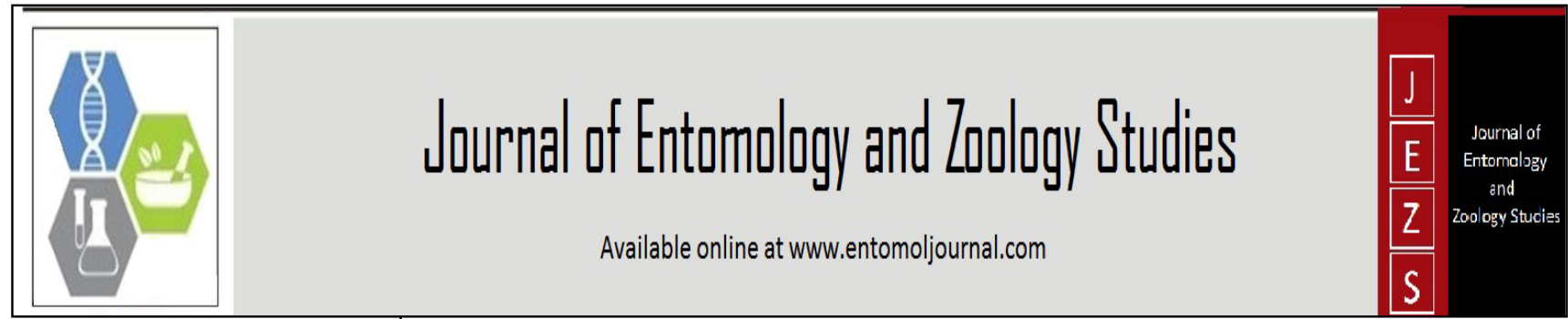

E-ISSN: 2320-7078 P-ISSN: 2349-6800 JEZS 2018; 6(1): 613-616

(C) 2018 JEZS

Received: 06-11-2017

Accepted: 07-12-2017

Mark Ian Cooper

Preller St, Muckleneuk, Pretoria, 0002, South Africa
Correspondence

Mark Ian Cooper

Preller St, Muckleneuk, Pretoria,

0002, South Africa

\title{
Sexual dimorphism in pill millipedes (Diplopoda)
}

\section{Mark Ian Cooper}

Abstract

Sexual size dimorphism (SSD) was investigated in the millipede genus Sphaerotherium. Width was extracted from Attems (1928) monograph and used to compare interspecific variation in mean volumes using a geometric morphometric approach. Based on the formula for a sphere $\left(4 / 3 . \pi \cdot \mathrm{r}^{3}\right)$, volume was calculated in seven species and an allometric coefficient of 0.7 found. The allometric equation generated for the genus was $\hat{\mathrm{y}}=0.00251 X+57211.22445$. Correlation between SSD and body sizes $(\mathrm{R}=0.749728$; $\mathrm{P}=0.00202 ; \mathrm{n}=7$ ) does now reject Rensch's rule in Sphaerotherium.

Keywords: Allometry, pill millipede, Rensch's rule, Sphaerotherium

\section{Introduction}

Diplopoda are underrepresented in allometric analyses of SSD, although sexual differences are known in body mass, length, width and leg dimensions of over half the taxa studied ${ }^{[1-3]}$. Size differences occur with factors such as color, sexes, species, urbanisation and water relations [4${ }^{8]}$. Diplopoda resemble the majority of invertebrates where SSD is reversed ${ }^{[9]}$. SSD has consequences for the outcome of sexual encounters in diplopod mating ${ }^{[10-14]}$. The detection of a relationship between body size and SSD is known as Rensch's rule ${ }^{[15-16]}$. Rensch's rule may be explained as sexual selection ${ }^{[17-21]}$. The macro-evolutionary pattern is being resolved in the class Diplopoda ${ }^{[53-54]}$

In the present study, SSD in the genus Sphaerotherium was investigated. Sphaerotherium consists of a large number of pill millipedes with some 54-60 described tropical and subtropical species extending to the Cape Peninsula in South Africa ${ }^{[22-24]}$. Individuals of both sexes roll into a spherical ball, which is part of the mating system ${ }^{[25]}$. Rensch's rule was tested, which predicts SSD negatively correlates with mean body sizes ${ }^{[15]}$.

\section{Material and Methods}

One factor was measured from Sphaerotherium species: (1) body width (mm), extracted from trusted published data ${ }^{[26]}$ and intersexual comparisons performed using Wilcoxon matched pairs tests. Size was perceived as body volume and calculated based on a geometric morphometric approach using the formula for a sphere $\left(4 / 3 . \pi \cdot r^{3}\right)$ where $r$ is half the width. SSD was estimated as mean female volume divided at mean male volume and converted into a SSD index by subtracting $1^{[27]}$. Allometry for SSD was based on an allometric model where male size $=\alpha(\text { female size })^{\beta[28]}$.

\subsection{Statistical analysis}

SSD were calculated using Microsoft Office Excel mathematical and statistical formula. Male and female widths were halved, cubed and multiplied at pi using a combination of mental arithmetic, power and product functions. Once calculated, species body volume or estimated species size was treated as the dependent $y$-variable or factor and measurements of mass were treated as the independent $\mathrm{x}$-variables which were inserted into the Spearman's Rho online calculator (http://www.socscistatistics.com/tests/spearman/Default2.aspx). Similarly for the linear regression, volume and SSD were inserted into the online calculator for linear regression available at http://www.socscistatistics.com/tests/regression/Default.aspx. Calculations were performed and a regression was calculated and Spearman's Rho coefficients calculated at http://www.socscistatistics.com/tests/spearman/Default2.aspx. Male and female width and volume was compared for differences in magnitude using the Wilcoxon matched pairs test available at http://www.socscistatistics.com/tests/signedranks/Default.aspx. 


\section{Results}

In 7 measurements where mean species sexual size dimorphism based on the spherical approximation (Table 1, $\mathrm{n}=7)$, width was larger in females than males $(\mathrm{Z}=-2.3664$; $\mathrm{W}=0 ; \mathrm{N}=7 ; p \leq 0.01$ ) and volume was significantly different between the sexes. There was a positive correlation between the $\log$ (male volume) on $\log$ (female volume) $(\mathrm{R}=0.700557$; $\mathrm{P}=0.00526 ; \mathrm{N}=7)$. At normal standards, the association between the two variables would be considered statistically significant. SSD ratios (female: male) for volume ranged from $0.492-4.359$ (Mean $\pm \mathrm{SD}=1.97 \pm 0.30)$. SSD was positively correlated with body size $(\mathrm{R}=0.749728 ; \mathrm{P}=0.00202 ; \mathrm{n}=7)$. At normal standards, the association between the two variables would be considered statistically significant. The allometric equation generated for the genus was $\hat{\mathrm{y}}=0.00251 \mathrm{X}$ +57211.22445 .

Table 1: Male and female morphometric parameters calculated in Sphaerotherium millipedes. Values are given as the mean measurements of sizes based on Attems' ${ }^{[26]}$ widths.

\begin{tabular}{|c|c|c|c|c|c|c|}
\hline Species & $\begin{array}{c}\text { Male } \\
\text { Width } \\
(\mathbf{m m})\end{array}$ & $\begin{array}{c}\text { Male } \\
\text { Volume } \\
\mathbf{( m m}^{\mathbf{3}} \mathbf{)}\end{array}$ & $\begin{array}{c}\text { Log } \\
\text { Male } \\
\text { Volume }\end{array}$ & $\begin{array}{c}\text { Female } \\
\text { Width } \\
\mathbf{( m m )}\end{array}$ & $\begin{array}{c}\text { Female } \\
\text { Volume } \\
\mathbf{( m m}^{\mathbf{3}} \mathbf{)}\end{array}$ & $\begin{array}{c}\text { Log } \\
\text { Female } \\
\text { Volume }\end{array}$ \\
\hline S. cinctellum & 15.5 & 1949.816 & 3.290 & 18.6 & 3369.283 & 3.528 \\
\hline S. commune & 6.0 & 113.097 & 2.053 & 9.5 & 448.921 & 2.652 \\
\hline S. compressum & 10.75 & 650.65 & 2.813 & 16.5 & 2352.071 & 3.371 \\
\hline S. punctulatum & 12 & 904.7787 & 2.957 & 21 & 4849.048 & 3.686 \\
\hline S. spinatum & 11.5 & 796.328 & 2.901 & 15 & 1767.146 & 3.247 \\
\hline S. tenuitarse & 7.0 & 179.594 & 2.254 & 8 & 268.083 & 2.428 \\
\hline S. tuberosum & 6.75 & 161.031 & 2.207 & 9 & 381.704 & 2.582 \\
\hline
\end{tabular}

Table 2: Sexual Size Dimorphism (SSD) calculated in seven species of Sphaerotherium pill millipedes relative to average body size $\left(\mathrm{mm}^{3}\right)$.

\begin{tabular}{|c|c|c|c|}
\hline Species & SSD & SSD-1 & Body Size $\left.\mathbf{( m m}^{\mathbf{3}}\right)$ \\
\hline S. cinctellum & 1.73 & 0.728 & 2659.55 \\
\hline S. commune & 3.97 & 2.969 & 281.0089 \\
\hline S. compressum & 3.62 & 2.616 & 1501.268 \\
\hline S. punctulatum & 5.36 & 4.3594 & 2876.913 \\
\hline S. spinatum & 2.21 & 1.219 & 1281.737 \\
\hline S. tenuitarse & 1.49 & 0.492 & 223.8385 \\
\hline S. tuberosum & 2.37 & 1.37 & 271.3673 \\
\hline
\end{tabular}

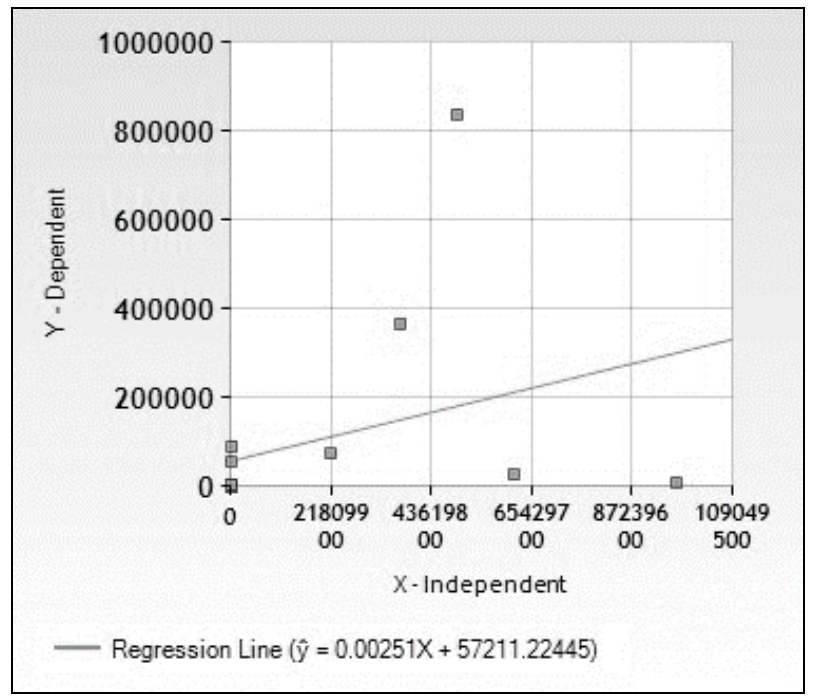

Fig 1: Regression showing the correlation between sexual size dimorphism and body size for pill millipedes (Sphaerotherium; $\mathrm{N}=$ 7)

\section{Discussion}

The significant difference in mean species widths, indicate selection for larger female size but does not exclude selection for male length. This could in itself be useful in assessing the contraction versus elongation hypotheses for the evolution of the millipede form ${ }^{[1]}$. The regression of SSD on body size indicates a positive correlation in Sphaerotherium and rejected Rensch's rule as was the pervading case for many taxa having female-biased SSD ${ }^{[29-53]}$. Mean volume ratios in
Sphaerotherium suggest relatively high variance of SSD ranging from 1.49 in $S$. tenuitarse to 5.36 in $S$. punctulatum which were both larger than helminthomorph diplopods ${ }^{[54]}$. The inclusion of many more taxa as new species from this genus is suggested to show support the trend of larger females as seen here. The identification of species specific and intraspecific sexual size dimorphism patterns using a phylogenetic approach may provide useful information for exploring mating systems further ${ }^{[55]}$. Tree climbing behaviour suggests interspecific competition drives the SSD ${ }^{[56]}$.

\section{Conclusion}

Rensch's rule tested and rejected in Sphaerotherium pill millipedes and support trends of sexual shape dimorphism with body size increases as in taxa with female-biased SSD.

\section{Acknowledgements}

University of South Africa student number 58536396.

\section{References}

1. Hopkin SP, Read HJ. The Biology of Millipedes. Oxford University Press, U. K., 1992, 246.

2. Ilić BS, Mitić BM, Makarov SE. Sexual dimorphism in Apfelbeckia insculpta (L. Koch, 1867) (Myriapoda: Diplopoda: Callipodida). Archives of Biological Sciences. 2017; 69:23-33.

3. Wilson HM, Anderson LI. Morphology and taxonomy of Paleozoic millipedes (Diplopoda: Chilognatha: Archipolypoda) from Scotland. Journal of Paleontology 2004; 78(1):169-184.

4. Bhakat S. Comparative water relations of some tropical millipedes. Kragujevac Journal of Science. 2014; 36:185194.

5. Bogyó D, Magura T, Simon E, Tóthmérész B. Millipede (Diplopoda) assemblages alter drastically by urbanisation. Landscape and Urban Planning. 2015; 133:118-126.

6. Calligaris IB, Boccardo L, Sanches MR, Fontanetti CS. Morphometric Analysis of a Population of Diplopods of the Genus Rhinocricus Karsch, 1881. Folia Biologica (Praha). 2005; 51:40-46.

7. David JF. Size criteria for the distinction between Cylindroiulus londinensis (Leach) and Cylindroiulus 
caeruleocinctus (Wood) (Diplopoda: Julidae). Journal of Natural History 1995; 29:983-991.

8. Enghoff H. The size of a millipede. In: Meyer E, Thaler $\mathrm{K}$, Schedl W (eds.) Advances in Myriapodology. Berichte des naturwissenschaftlich-medizinischen Vereins in Innsbruck, Supplement 1992; 10:47-56.

9. Mori E, Mazza G, Lovari S. Sexual Dimorphism. In: Encyclopedia of Animal Cognition and Behavior. J. Vonk, Shakelford, T, Springer International Publishing, Switzerland, 2017, 1-7.

10. Adolph SC, Geber MA. Mate-Guarding, Mating Success and Body Size in the Tropical Millipede 'Nyssodesmus Pythos' (Peters) (Polydesmida: Platyrhacidae). The Southwestern Naturalist. 1995; 40(1):56-61.

11. Rowe M. Copulation, mating system and sexual dimorphism in an Australian millipede, Cladethosoma clarum. Australian Journal of Zoology. 2010; 58(2):127132.

12. Cooper MI. Size matters in myriapod copulation. Journal of Entomology and Zoology Studies. 2017; 5(2):207-208.

13. Tanabe T, Sota T. Complex Copulatory Behavior and the Proximate Effect of Genital and Body Size Differences on Mechanical Reproductive Isolation in the Millipede Genus Parafontaria. The American Naturalist. 2008; 171(5):692-699.

14. Cooper MI. The affect of female body width on copulation duration in Centrobolus inscriptus (Attems). Journal of Entomology and Zoology Studies. 2017; 5(1):732-733.

15. Rensch B. Evolution above the Species Level. Columbia, New York, 1947, 419.

16. Rensch B. Die Abhängigkeit der relativen Sexualdifferenz von der Körpergrösse. Bonn Zoological Bulletin. 1950; 1:58-69.

17. Andersson M, Wallander J. Animal behaviour: Relative size in the mating game. Nature 2004; 431:139-141.

18. Bonduriansky R. Sexual selection and allometry: a critical reappraisal of the evidence and ideas. Evolution. 2007; 61(4):838-849.

19. Clutton-Brock TH, Harvey PH, Rudder B. Sexual dimorphism, socionomic sex ratio and body weight in primates. Nature. 1977; 269:797-800.

20. Dale J, Dunn PO, Figuerola J, Lislevand T, Székely T, Whittingham LA. Sexual selection explains Rensch's rule of allometry for sexual size dimorphism. Proceedings of the Royal Society B. 2007; 274:2971-2979.

21. Gaulin SJC, Sailer LD. Sexual dimorphism in weight among the Primates: the relative impact of allometry and sexual selection. International Journal of Primatology. 1984; 5(6):515-535.

22. Cooper MI Sexual size dimorphism and corroboration of Rensch's rule in Chersastus millipedes. Journal of Entomology and Zoology Studies 2014; 2(6):264-266.

23. Van den Spiegel D, Golovatch SI, Hamer ML. Revision of some of the oldest species in the millipede genus Sphaerotherium Brandt, 1833 (Diplopoda, Sphaerotheriida, Sphaerotheriidae), with new synonymies. African Invertebrates. 2002; 43:143-181.

24. Cooper MI. Pill millipedes. African Wildlife. 58(2):44.

25. Wesener T. The Giant Pill-Millipedes, order Sphaerotheriida - An annotated species catalogue with morphological atlas and list of apomorphies (Arthropoda: Diplopoda). Bonn zoological Bulletin - Supplementum. 2016; 63:1-104.

26. Wesener T, Köhler J, Fuchs S, Van den Spiegel D. How to uncoil your partner- "mating songs" in giant pillmillipedes (Diplopoda: Sphaerotheriida). Naturwissenschaften. 2011; 98:967-975.

27. Attems C. The Myriapoda of South Africa. Annals of the South African Museum. 1928; 26:1431.

28. Lovich JE, Gibbons JW. A review of techniques for quantifying sexual size dimorphism. Growth Development and Aging. 1992; 56:269-281.

29. Leutenegger W. Scaling of sexual dimorphism in body size and breeding system in primates. Nature. 1978; 272:610-611.

30. Lindenfors P, Tullberg BS, Biuw M. Phylogenetic analyses of sexual selection and sexual size dimorphism in pinnipeds. Behavioural Ecology and Sociobiology. 2002; 52:188-193.

31. Monnet JM, Cherry MI. Sexual size dimorphism in anurans. Proceedings of the Royal Society of London B Biological Sciences. 2002; 269(1507):2301-2307.

32. Jannot JE, Kerans BL. Body size, sexual size dimorphism, and Rensch's rule in adult hydropsychid caddisflies (Trichoptera: Hydropsychidae). Canadian Journal of Zoology. 2003; 81:1956-1964.

33. Tubaro PL, Bertelli S. Female-biased sexual size dimorphism in tinamous: a comparative test fails to support Rensch's rule. Biological Journal of the Linnean Society. 2003; 80:519-527.

34. Rutherford PL. Proximate mechanisms that contribute to female-biased sexual size dimorphism in an anguid lizard. Canadian Journal of Zoology. 2004; 82(5):817822 .

35. Teder T, Tammaru T. Sexual size dimorphism within species increases with body size in insects. Oikos. 2005; 108:321-334.

36. Webb TJ, Freckleton RP. Only Half Right: Species with Female-Biased Sexual Size Dimorphism Consistently Break Rensch's Rule. PLoS ONE. 2007; 2(9):e89715.

37. Sutter NB, Mosher DS, Ostrander EA. Morphometrics within dog breeds are highly reproducible and dispute Rensch's rule. Mammalian Genomics. 2008; 19:713-723.

38. Stuart-fox D. A test of Rensch's rule in dwarf chameleons (Bradypodion spp.), a group with femalebiased sexual size dimorphism. Evolutionary Ecology. 2009; 23:425-433.

39. Herczeg G, Gonda A, Merilä J. Rensch's rule inverted female-driven gigantism in nine-spined stickleback Pungitius pungitius. Journal of Animal Ecology. 2010; 79:581-588.

40. Remeš V, Székely T. Domestic chickens defy Rensch's rule: sexual size dimorphism in chicken breeds. Journal of Evolutionary Biology. 2010; 23:2754-2759.

41. Minton RL, Wang LL. Evidence of sexual shape dimorphism in Viviparus (Gastropoda: Viviparidae). Journal of Molluscan Studies. 2011; 77(3):315-317.

42. Liao WB, Chen W. Inverse Rensch-rule in a frog with female-biased sexual size dimorphism. Naturwissenschaften. 2012; 99:427-431.

43. Bidau CJ, Martí DA, Castillo ER. Rensch's rule is not verified in melanopline grasshoppers (Acrididae). Journal of Insect Biodiversity. 2013; 1(12):1-14.

44. De Lisle SP, Rowe L. Correlated Evolution of Allometry and Sexual Dimorphism across Higher Taxa. The American Naturalist. 2013; 182(5):630-639.

45. Liao WB, Zeng Y, Zhou CQ, Jehle R. Sexual size dimorphism in anurans fails to obey Rensch's rule. Frontiers in Zoology. 2013; 10(10):1-7. 
46. Liao WB. Evolution of sexual size dimorphism in a frog obeys the inverse of Rensch's rule. Evolutionary Biology. 2013; 40:493-499.

47. Colleoni E, Denoël M, Padoa-Schioppa E, Scali S, Ficetola GF. Rensch's rule and sexual dimorphism in salamanders: patterns and potential processes. Journal of Zoology. 2014; 293:143-151.

48. Guillermo-Ferreira R, Novaes MC, Lecci LS, Bispo PC. Allometry for Sexual Size Dimorphism in Stoneflies Defies the Rensch's Rule. Neotropical Entomology. 2014; 43:172-175.

49. Husak JF, McGuire JA. Does 'gliding while gravid' explain Rensch's rule in flying lizards? Biological Journal of the Linnean Society. 2014; 113:270-282.

50. Lu D, Zhou CQ, Liao WB. Pattern of sexual size dimorphism supports the inverse Rensch's rule in two frog species. Animal Biology. 2014; 64:87-95.

51. Liao WB, Liu WC, Merilä J. Andrew meets Rensch: sexual size dimorphism and the inverse of Rensch's rule in Andrew's toad (Bufo andrewsi). Oecologia. 2015; 177:389-399.

52. Cooper MI. The relative sexual size dimorphism of Centrobolus inscriptus (Attems) compared to 18 congenerics. Journal of Entomology and Zoology Studies. 2016; 4(6):504-505.

53. Martin OY, Michalczyk L, Millard AL, Emerson BC, Gage MJG. Lack of support for Rensch's rule in an intraspecific test using red flour beetle (Tribolium castaneum) populations. Insect Science. 2017; 24(1):133140.

54. Cooper MI. Re-assessment of Rensch's rule of Centrobolus. Journal of Entomology and Zoology Studies 2017; 5(6):2408-2410.

55. Cooper MI. Allometry for sexual dimorphism in diplopods. Journal of Entomology and Zoology Studies 2018; 6(1):91-96.

56. Wesener T. A new phylogenetic analysis of the Sphaerotheriida (Diplopoda) with a revision of the Australian giant pill-millipedes. Invertebrate Systematics. 2014; 28:196-213

57. Haacker U, Fuchs S. Tree-Climbing in pill-millipedes. Oecologia. 1972; 10(2):191-192. 